\title{
Effect of the 5-lipoxygenase inhibitor ZD2138 on allergen-induced early and late asthmatic responses
}

\author{
S M Shuaib Nasser, Gail S Bell, Richard J Hawksworth, Karen E Spruce, \\ Rodger MacMillan, Andrew J Williams, Tak H Lee, Jonathan P Arm
}

\begin{abstract}
Background - Leukotrienes are lipid mediators generated from arachidonic acid by the 5-lipoxygenase pathway which may play an important part in the pathophysiology of asthma. Previous studies have demonstrated attenuation of the allergen-induced early and late asthmatic responses by leukotriene receptor antagonists. The effect of the 5-lipoxygenase inhibitor ZD2138, a non-redox lipoxygenase inhibitor which inhibits leukotriene synthesis for 24 hours after single doses of $350 \mathrm{mg}$, on allergen-induced early and late asthmatic responses has been
\end{abstract} assessed.

Methods - Eight asthmatic subjects with baseline $\mathrm{FEV}_{1}>70 \%$ were studied. On screening, all subjects developed an allergen-induced biphasic asthmatic response to grass pollen, cat dander, or house dust mite. ZD2138 (350 mg) or placebo was given on two occasions separated by two weeks in a randomised double blind fashion. Allergen inhalation challenge was performed four hours after dosing and FEV $_{1}$ was measured for eight hours. The inhibitory activity of ZD2138 on the 5lipoxygenase pathway was assessed by measurements of calcium ionophorestimulated generation of $\mathrm{LTB}_{4}$ in whole blood ex vivo and by analysis of urinary $\mathrm{LTE}_{4}$ levels before administration of drug or placebo and at regular intervals after oral drug dosing and allergen challenge. Results - ZD2138 produced no significant bronchodilatation or attenuation of the early or late asthmatic response, although there was $82 \%$ inhibition of whole blood generation of $\mathrm{LTB}_{4}$ in response to calcium ionophore stimulation and $52 \%$ reduction in urinary excretion of $\mathrm{LTE}_{4}$.

Conclusions - In asthmatic subjects the 5lipoxygenase inhibitor ZD2138 did not protect against allergen-induced asthmatic responses, despite substantial inhibition of 5-lipoxygenase.

(Thorax 1994;49:743-748)
Leukotrienes are lipid mediators derived from the oxidative metabolism of arachidonic acid by the 5-lipoxygenase pathway. $\mathrm{LTB}_{4}$ has potent chemoattractant properties for granulocytes and monocytes, ${ }^{1-4}$ enhances complement receptor expression, ${ }^{23}$ increases neutrophil adherence to endothelium, ${ }^{5}$ and causes neutrophil aggregation and degranulation. ${ }^{36}$ The cysteinyl leukotrienes $\mathrm{LTC}_{4}, \mathrm{LTD}_{4}$, and $\mathrm{LTE}_{4}$ are potent bronchoconstrictors, ${ }^{7}$ stimulate bronchial mucus secretion, ${ }^{89}$ increase venopermeability, ${ }^{1011}$ and increase airways hyperresponsiveness of asthmatic subjects. ${ }^{1213}$ Leukotrienes have been recovered from asthmatic airways by bronchoalveolar lavage ${ }^{14-17}$ and increased levels of $\mathrm{LTE}_{4}$ have also been detected in the urine of asthmatic subjects during an acute asthma attack $^{1819}$ and following allergen challenge. ${ }^{1820-22}$ Both early and late asthmatic responses and the increased airway hyperresponsiveness provoked by allergen challenge are attenuated by administration of cysteinyl leukotriene receptor antagonists. ${ }^{23-26}$ An alternative way to inhibit the action of leukotrienes is to inhibit their biosynthesis. We have therefore evaluated the effect of a novel 5-lipoxygenase inhibitor, ZD2138 (previously reported as ICI D2138), on allergen-induced asthma. ZD2138 is a non-redox lipoxygenase inhibitor ${ }^{27}$ which is well tolerated and, at single oral doses of $350 \mathrm{mg}$ and above, inhibits leukotriene synthesis for 24 hours. ${ }^{28}$

\section{Methods}

SUBJECTS

Eight non-smoking atopic men with asthma of mean age 27 (range 23-37) years were studied (table). Their mean (SE) resting forced expiratory volume in one second $\left(\mathrm{FEV}_{1}\right)$ was 4.02 (0.25) l (mean predicted $97 \%$; range $74-124 \%$ ). One subject took no medication, one took regular inhaled beclomethasone dipropionate $(200 \mu \mathrm{g}$ daily), salmeterol $(200 \mu \mathrm{g}$ daily) and salbutamol as required, and six subjects took salbutamol as required. All subjects had positive immediate skin weal reactions to either cat dander, Dermatophagoides pteronyssinus, or grass pollen (Phleum pratense). The study was approved by the Guy's Hospital ethics committee and written informed consent was obtained from each subject. 
Age, baseline FEV, values, medication, and allergen used for bronchial provocation in the eight subjects

\begin{tabular}{lllcll}
\hline Subject & $\begin{array}{l}\text { Age } \\
\text { (years) }\end{array}$ & $\begin{array}{l}\text { FEV } \\
\text { (litres) }\end{array}$ & $\begin{array}{l}\% \text { predicted } \\
\text { FEV }\end{array}$ & Drugs & Allergen \\
\hline 1 & 26 & $3 \cdot 29$ & 74 & S & GP \\
2 & 25 & 4.96 & 105 & S, B, SM & DP \\
3 & 37 & $4 \cdot 11$ & 98 & - & GP \\
4 & 24 & $3 \cdot 98$ & 102 & S & Cat \\
5 & 26 & $3 \cdot 43$ & 93 & S & DP \\
6 & 27 & $5 \cdot 2$ & 124 & S & GP \\
7 & 30 & 3.67 & 92 & S & DP \\
8 & 23 & 3.51 & 88 & S & Cat \\
\hline
\end{tabular}

$\mathrm{S}=$ salbutamol; $\mathrm{B}=$ beclomethasone dipropionate; $\mathrm{SM}=$ salmeterol; $\mathrm{GP}=$ grass pollen; $\mathrm{DP}=\mathrm{Der}$ matophagoides pteronyssinus; $\mathrm{Cat}=\mathrm{cat}$ dander.

STUDY PROTOCOL

Subjects were studied on three days, each separated by two weeks. On day 1 a medical history was taken and the subjects underwent general physical examination with an ECG. Blood was taken for a full blood count, clotting studies, estimation of electrolytes and urea, and liver function tests. Urine was examined by microscopy and tested for glucose, protein, and blood. Skin testing and inhaled allergen challenge were then performed. Subjects with a $20 \%$ or greater fall in $\mathrm{FEV}_{1}$ within 15 minutes of allergen inhalation (early response) and at 4 8 hours after allergen challenge (late response) continued with study days 2 and 3 . Salmeterol was discontinued for 48 hours, inhaled corticosteroids for 24 hours, and salbutamol for at least eight hours before each study day until 24 hours after allergen challenge.

On days 2 and $3350 \mathrm{mg}$ ZD2138 (Zeneca Pharmaceuticals, Macclesfield, Cheshire, UK) or matching placebo was given after an overnight fast in a randomised, double blind fashion. Four hours later allergen challenge was performed as on day 1 . Continuous ambulatory ECG was monitored on days 2 and 3 for 24 hours. Urine was collected before drug or placebo administration and then immediately before and three, six, and nine hours after allergen challenge. The patients did not pass urine between the specified collection times. Blood for determination of ex vivo $\mathrm{LTB}_{4}$ generation was taken before and four (pre-allergen), 12, and 24 hours after drug administration. Days 2 and 3 were separated by two weeks.

\section{SKIN TESTING}

Subjects were prick tested to cat dander, Dermatophagoides pteronyssinus, and grass pollen (ALK, Horsholm, Denmark) at a concentration of 81920 square units/ml of Coca's solution (4\% phenol, $2.75 \%$ sodium bicarbonate, and $5 \%$ sodium chloride (w:v)). The allergen producing the largest weal diameter was chosen for a dose ranging study of 12 doubling dilutions in Coca's solution. One doubling dilution less than that producing a skin weal of $2 \mathrm{~mm}$ greater than diluent alone was chosen as the starting dilution for bronchial provocation.

SPIROMETRY AND ALLERGEN CHALLENGE

Two recordings of $\mathrm{FEV}_{1}$ were made with a dry wedge bellows spirometer (Vitalograph Ltd, Buckingham, UK) at each time point and the highest value was used. Further readings were only made if the first two values were not within $10 \%$ or were technically inadequate. Nebulised solutions of Coca's solution and allergen were administered at room temperature using a Hudson nebuliser (Henleys Medical Supplies, Middlesex, UK) linked to a breath actuated dosimeter. Delivery of air to the nebuliser was regulated to a pressure of $138 \mathrm{kPa}(20 \mathrm{psi}$ ) for a duration of 0.6 seconds from the start of each breath. There was no time lag between inspiration and actuation of the dosimeter. Under these conditions the nebuliser delivers droplets with a mass median aerodynamic diameter of $1.6 \mu \mathrm{m}$ and the output of the nebuliser is $2.6 \mu 1$ per actuation. After baseline measurements of $\mathrm{FEV}_{1}$ the subjects inhaled five breaths of Coca's solution as control. Each dose consisted of five submaximal breaths starting at functional residual capacity followed by a five second breath hold. If the decrease in $\mathrm{FEV}_{1}$ following Coca's solution was $<10 \%$ the subjects underwent allergen challenge. Incremental doubling concentrations of allergen diluted in Coca's solution were used for bronchial challenge at 15 minute intervals with $\mathrm{FEV}_{1}$ measurements at 5 , 10 , and 15 minutes until a fall in $\mathrm{FEV}_{1}$ of at least $20 \%$ was achieved. Further measurements of $\mathrm{FEV}_{1}$ were made at 20,30, and 60 minutes and then hourly until eight hours after allergen challenge. Subsequent allergen challenges on days 2 and 3 were performed using the final three allergen concentrations leading to a $20 \%$ fall in $\mathrm{FEV}_{1}$ and were given sequentially at 10 minute intervals. The coefficient of repeatability of the early and late asthmatic reactions following allergen challenge in 26 subjects in our laboratory is $38 \%$ and $27 \%$ respectively. All eight subjects were given $200 \mu \mathrm{g}$ salbutamol routinely at the end of the period of urine collection. No subject required treatment.

MEASUREMENT OF URINARY LTE $_{4}$

The free radical scavenger 4-hydroxy-2,2,6,6tetramethylpiperidinooxy free radical (4-hydroxy-TEMPO; Sigma Chemical Company, Poole, Dorset, UK) was added to each urine sample immediately after collection to a final concentration of $1 \mathrm{mmol} / \mathrm{l}$, the samples were adjusted to $\mathrm{pH} 9$ with $\mathrm{NaOH}$ to stabilise endogenous leukotriene metabolites and stored at $-70^{\circ} \mathrm{C}$ until analysed. Urinary $\mathrm{LTE}_{4}$ levels were measured as described previously. ${ }^{29}$ The stored urine samples were thawed and $50 \mu \mathrm{l}$ of a solution containing $\left[{ }^{3} \mathrm{H}\right] \mathrm{LTE}_{4}(128.5 \mathrm{Ci} / \mathrm{mmol}$; NEN, DuPont, Boston, USA) was added to $10 \mathrm{ml}$ urine to give 4000 disintegrations per minute as an internal standard. After adding $250 \mu \mathrm{l}$ glacial acetic acid to bring the $\mathrm{pH}$ to $3 \cdot 5-$ 3.8 the $10 \mathrm{ml}$ sample was loaded onto a $10 \mu \mathrm{m}$ precolumn (Ultrasil ODS, $3.4 \mathrm{~mm} \times 4.5 \mathrm{~cm}$, Beckman, USA) to wash off polar metabolites with a phosphate buffer $\left(0 \cdot 1 \% \quad \mathrm{NaH}_{2} \mathrm{PO}_{4}\right.$, pH 3.8) for eight minutes and then for 12 minutes with methanol:phosphate buffer in the proportions 50:50 (v:v). The sample was then retrogradely eluted onto a reversed phase analytical column (Ultrasil ODS $4.5 \mathrm{~mm} \times 25 \mathrm{~cm}$, Altex) that had been equilibrated in $62 \%$ 
methanol:37.8\% water: $0 \cdot 1 \%$ acetic acid: $0 \cdot 1 \%$ EDTA (v:v:v:w) at pH 5.6 at a flow rate of $1 \mathrm{ml} /$ min. One minute fractions were collected and the fraction containing peak radioactivity corresponding to the internal standard was identified by counting $250 \mu \mathrm{l}$ of the eluent in a $\beta$ liquid scintillation counter (Tricarb 1900CA, Packard Instrument Co, USA). The remaining $750 \mu \mathrm{l}$ of those fractions containing $\left[{ }^{3} \mathrm{H}\right] \mathrm{LTE}_{4}$ and the two fractions eluted before and after the peak were dried under vacuum and resuspended in $250 \mu \mathrm{l}$ of $10 \mathrm{mmol} / 1 \mathrm{Tris} \mathrm{HCl}$ buffer (pH 7.4). The concentration of immunoreactive $\mathrm{LTE}_{4}$ was assessed by radioimmunoassay as described previously. ${ }^{29} 30$

Samples to be measured or defined dilutions of standard $\mathrm{LTE}_{4}$ and rabbit anti- $\mathrm{LTC}_{4}$ (kind gift of Dr A Ford Hutchison, Merck Frosst, Dorral, Quebec, Canada) were incubated with labelled $\left[{ }^{3} \mathrm{H}\right] \mathrm{LTE}_{4}(128.5 \mathrm{Ci} / \mathrm{mmol}, \mathrm{NEN}$, Dupont, Boston, USA) in a total volume of $300 \mu \mathrm{l} \mathrm{Tris} \mathrm{HCl}$ buffer $\mathrm{pH} 7.4$ for one hour at room temperature. $200 \mu \mathrm{l}$ of $1 \% \mathrm{charcoal} / \mathrm{dex}$ tran was added to each tube to absorb unbound $\mathrm{LTC}_{4}$ and the tubes centrifuged at $2000 \mathrm{~g}$ for 15 minutes at $4^{\circ} \mathrm{C}$. The radioactivity of $400 \mu \mathrm{l}$ of the supernatant was counted in a liquid scintillation counter. The quantity of immunoreactive $\mathrm{LTE}_{4}$ was interpolated from a standard curve which was linear in the range $0.01-0.03 \mathrm{ng}$ $\mathrm{LTE}_{4}$. The $\mathrm{LTC}_{4}$ antibody binds to $\mathrm{LTC}_{4}$, $\mathrm{LTD}_{4}$, and $\mathrm{LTE}_{4}$ with $50 \%$ binding at $0.03 \mathrm{ng} /$ $\mathrm{ml}, 0.06 \mathrm{ng} / \mathrm{ml}$, and $0.09 \mathrm{ng} / \mathrm{ml}$ respectively.

Urinary creatinine concentrations were measured (Mira Analyser, Hoffman Roche, Welwyn) by the kinetic picrate method without deproteinisation. ${ }^{31} \mathrm{LTE}_{4}$ concentrations were expressed as $\mathrm{pg} / \mathrm{mg}$ creatinine and were calculated from measured immunoreactivity minus background, corrected for recovery and dilution.

MEASUREMENT OF EX VIVO $\mathrm{LTB}_{4}$

The ability of ZD2138 to inhibit 5-lipoxygenase was also assessed by measurement of cal-

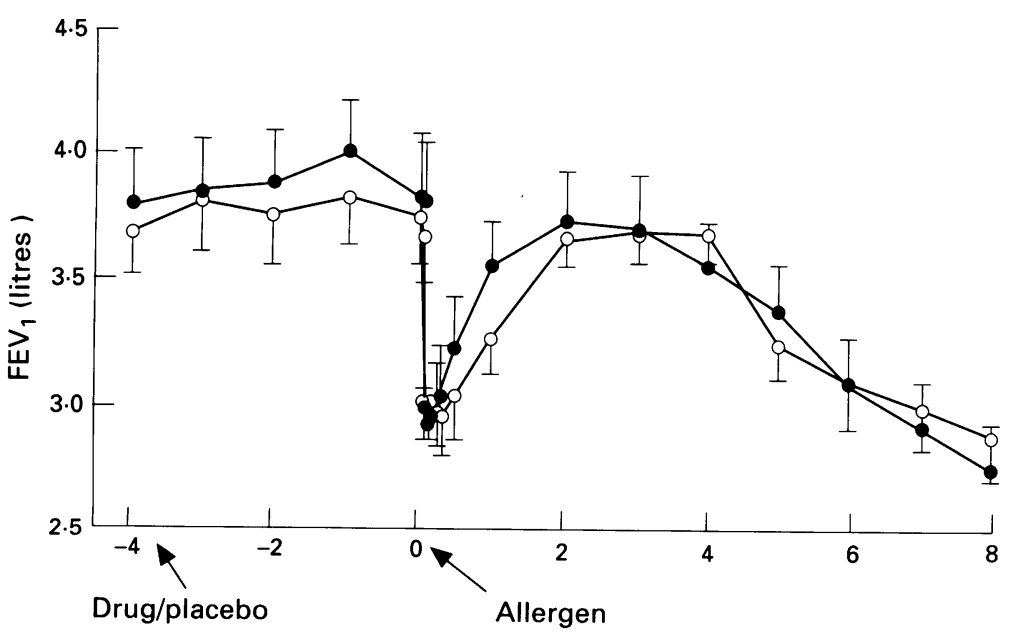

Time relative to administration of allergen (hours)

Figure 1 Time course of changes in FEV following treatment with ZD2138 (O) and placebo $(\bigcirc)$ before and after allergen challenge on each study day. Study medication was administered four hours before allergen challenge ( -4 hours) immediately after the $F E V$, measurement. Allergen challenge was performed at 0 time and FEV, was measured for eight hours afterwards. Each point denotes mean $(S E)$ of eight subjects. cium ionophore-stimulated ex vivo $\mathrm{LTB}_{4}$ production in whole blood. Blood was collected into heparinised tubes and calcium ionophore (A23187) was added to $500 \mu \mathrm{l}$ whole blood in triplicate to a final concentration of $2.5 \mu \mathrm{mol} / \mathrm{l}$. The blood was incubated for 20 minutes at $37^{\circ} \mathrm{C}$, centrifuged at $3600 \mathrm{rpm}$ for one minute, and the supernatant stored at $-20^{\circ} \mathrm{C}$. $\mathrm{LTB}_{4}$ was assayed subsequently by radioimmunoassay as previously described. ${ }^{32}$

The rabbit anti- $\mathrm{LTB}_{4}$ antibody used for radioimmunoassay only crossreacts significantly with 6-trans $\mathrm{LTB}_{4}(60 \%), 20-\mathrm{OH} \mathrm{LTB}$ $(41 \%)$, and $12(\mathrm{R}, \mathrm{S})$ HETE $(33 \%)$. Scatchard analysis showed this antibody to be of high affinity for $\mathrm{LTB}_{4}\left(\mathrm{Ka}=4.9 \times 10^{-11} \mathrm{~mol} / \mathrm{l}\right)$.

\section{DATA ANALYSIS}

Comparison of urinary $\mathrm{LTE}_{4}$ and whole blood $\mathrm{LTB}_{4}$ levels after ZD2138 and placebo were analysed non-parametrically using the Wilcoxon signed rank test on the individual areas under the concentration-time curves. Airway responses to allergen and the differential effect of placebo and ZD2138 were assessed by calculation of the area under the $\mathrm{FEV}_{1}$-time curves for the following periods: $0-4$ hours after drug administration to assess bronchodilator effect; 0-1 hour after allergen to assess the early asthmatic response; and 3-8 hours after allergen to assess the late asthmatic response. Comparisons between drug and placebo days were analysed using the Wilcoxon signed rank test of the area under the $\mathrm{FEV}_{1}$-time curves. Linear regression analysis was used to compare the percentage inhibition of urinary $\mathrm{LTE}_{4}$ and whole blood ex vivo $\mathrm{LTB}_{4}$ levels with both the early and late asthmatic responses. A p value of $<0.05$ was considered significant. Data are expressed as mean (SE).

\section{Results}

\section{AIRWAY RESPONSES}

There was no significant difference in baseline $\mathrm{FEV}_{1}$ before drug administration between the two study days. Figure 1 shows the mean change in $\mathrm{FEV}_{1}$ after administration of placebo or ZD2138 on study days 2 and 3. There was no significant bronchodilatation during the four hours after administration of ZD2138. The $\mathrm{FEV}_{1}$ values immediately before allergen challenge were $3.81(0.24) 1$ after ZD2138 and 3.68 $(0 \cdot 19) 1$ after placebo and were not significantly different. Although the $\mathrm{FEV}_{1}$-time curve during the early asthmatic response appeared to return to baseline sooner after ZD2138, there was no significant difference in the extent of the early or late asthmatic responses following allergen challenge between administration of ZD2138 and placebo as measured by the areas under the $\mathrm{FEV}_{1}$-time curves.

INHIBITION OF EX VIVO GENERATION OF $\mathrm{LTB}_{4}$ Figure 2 shows the mean ionophore-induced generation of $\mathrm{LTB}_{4}$ from whole blood after placebo and ZD2138. No difference between the two baseline $\mathrm{LTB}_{4}$ levels was found. There 


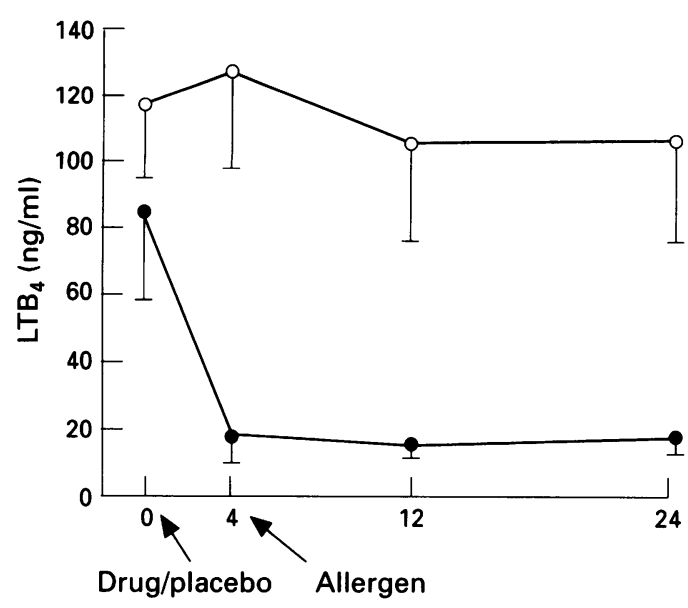

Time after ZD2138 or placebo administration (hours)

Figure 2 Whole blood ex vivo generation of $\mathrm{LTB}_{4}$ in response to $2.5 \mu \mathrm{mol} / \mathrm{l}$ A23187 before and after receiving ZD2138 (-) or placebo (O). Allergen was administered four hours after dosing. Each point denotes mean (SE) of eight subjects.

was a statistically significant difference between the ZD2138 and placebo days for the area under the curves $(p=0.01)$, with an $82 \%$ reduction in $\mathrm{LTB}_{4}$ generation on the ZD2138 day compared with placebo. Linear regression analysis demonstrated no significant correlation between percentage inhibition of ex vivo generation of whole blood $\mathrm{LTB}_{4}$ and the early $(r=0.55 ; \mathrm{p}=0.15)$ or late $(r=-0.12 ; \mathrm{p}=0.77)$ asthmatic response.

\section{URINARY LTE}

There was no significant difference between baseline urinary $\mathrm{LTE}_{4}$ levels on the two days (fig 3). Comparison of the area under the curves indicated a $52 \%$ reduction in urinary $\mathrm{LTE}_{4}$ excretion following ZD2138 compared with that observed after administration of placebo $(p=0.013)$. Linear regression analysis demonstrated no correlation between percentage inhibition of urinary $\mathrm{LTE}_{4}$ excretion and either the early $(r=0.53 ; \mathrm{p}=0.18)$ or the late $(r=-0.23$; $\mathrm{p}=0.58)$ asthmatic response.

ZD2138 was well tolerated and no adverse events attributed to the drug occurred in this study. All eight subjects completed the study.

\section{Discussion}

There is increasing evidence that leukotrienes may contribute to the inflammation of the airways, hyperresponsivenes of the airways, and the acute bronchospasm that characterise bronchial asthma. In support of this hypothesis leukotrienes have been recovered from the bronchoalveolar lavage fluid of asthmatic subjects at rest $^{1415}$ and following challenge with allergen $^{1617}$ and isocapnic hyperventilation..$^{33}$ Increased urinary excretion of $\mathrm{LTE}_{4}$ has been demonstrated during acute severe asthma ${ }^{1819}$ and following allergen-induced asthma. ${ }^{1820-22}$ If leukotrienes are important in asthma, then drugs which inhibit their generation or antagonise their action should inhibit asthmatic responses.

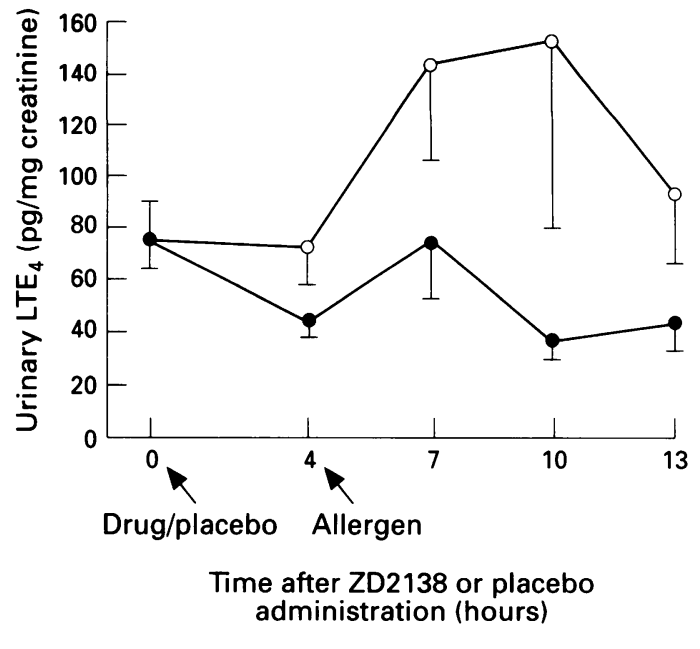

Figure 3 Urinary $\mathrm{LTE}_{4}$ levels before and after receiving ZD2138 (O) or placebo ( $O$ ). Allergen was administered four hours after dosing. Each point denotes mean (SE) of eight subjects except at 13 hours where $n=6$.

In this study we evaluated the effect of a 5lipoxygenase inhibitor on allergen-induced asthma. ZD2138 was developed from a class of 5-lipoxygenase inhibitors that inhibit the enzyme via an enantioselective mechanism. ${ }^{34}$ In vitro data on whole blood show that it is the most potent and most selective 5-lipoxygenase inhibitor yet reported, ${ }^{27}$ and has a half life after absorption of 12 hours. Inhibition of 5-lipoxygenase, which is both maximal $(>90 \%)$ and sustained for 24 hours, is obtained at a plasma concentration of $80 \mathrm{ng} / \mathrm{ml}$ which is achieved with a dose of $350 \mathrm{mg}$ or more. Subjects were fasted in the present study to standardise oral bioavailability. 5-lipoxygenase activity was monitored by measuring whole blood generation of $\mathrm{LTB}_{4}$ in response to calcium ionophore, and by measuring urinary excretion of $\mathrm{LTE}_{4}$ following allergen challenge. Administration of ZD2138 led to an $86 \%$ inhibition in whole blood generation of $\mathrm{LTB}_{4}$ at four hours after dosing immediately before allergen challenge, $85 \%$ inhibition of whole blood $\mathrm{LTB}_{4}$ generation 12 hours after dosing during the late asthmatic response, and $83 \%$ inhibition at 24 hours after dosing. Administration of ZD2138 led to a significant decrease in urinary excretion of $\mathrm{LTE}_{4}$ before allergen challenge and attenuated the allergen-induced rise in urinary $\mathrm{LTE}_{4}$ excretion which was observed on the placebo day. Despite this evidence for effective inhibition of 5-lipoxygenase activity there was no attenuation of early or late asthmatic responses to allergen following administration of ZD2138. These findings are in agreement with those of Hul et al who found no effect of the 5lipoxygenase inhibitor Zileuton on allergeninduced asthma, ${ }^{35}$ and are in contrast to the efficacy of leukotriene receptor antagonists in allergen-induced asthma. ${ }^{23-26}$

There are several possible explanations for the lack of efficacy of 5-lipoxygenase inhibitors in allergen-induced asthma. Firstly, it is possible that leukotrienes do not contribute significantly to allergen-induced asthmatic reactions. This possibility seems unlikely since leukotrienes are released at the time of allergen 
challenge ${ }^{16-21}$ and the more potent $\mathrm{LTD}_{4}$ receptor antagonists attenuate allergen-induced asthmatic responses. ${ }^{23-26}$ Secondly, there may have been insufficient attenuation of leukotriene generation within the airway. This possibility cannot be excluded although the administration of ZD2138 inhibited ionophore-induced generation of $\mathrm{LTB}_{4}$ in whole blood and attenuated the allergen-induced rise in $\mathrm{LTE}_{4}$ excretion in the urine. Nevertheless it should be emphasised that neither of these assays document pulmonary release of leukotrienes alone. A third possibility is that 5-lipoxygenase inhibition in the lung diverted allergen-induced arachidonic acid metabolism to the generation of bronchoconstrictor prostaglandins via the cyclooxygenase pathway. Finally, it is possible that 5lipoxygenase inhibition attenuates the generation not only of leukotrienes, but also of double lipoxygenase products such as the lipoxins. ${ }^{36}$ Lipoxins are formed by the combined activity of 5-lipoxygenase and 15-lipoxygenase. Lipoxin $\mathrm{A}_{4}\left(\mathrm{LXA}_{4}\right)$, the major isomer, inhibits guinea pig pulmonary responses to $\mathrm{LTC}_{4}$ in vitro $^{36}$ and inhalation of $\mathrm{LXA}_{4}$ in asthmatic subjects inhibited the bronchoconstrictor response to $\mathrm{LTC}_{4}{ }^{37}$ Inhibition of 5-lipoxygenase may lead to decreased generation of $\mathrm{LXA}_{4}$ resulting in a loss of its protective effect against residual leukotrienes within the airway. This could explain the absence of the protective effect of ZD2138 in allergen challenge and would also account for the difference in efficacy of 5-lipoxygenase inhibitors and sulphidopeptide leukotriene receptor antagonists in preventing allergen-induced asthmatic reactions. Lipoxin generation was not measured in this study and so this hypothesis was not tested.

Although 5-lipoxygenase inhibition is ineffective in, attenuating allergen-induced asthma, it is known that the 5-lipoxygenase inhibitor Zileuton (A64077) inhibited the airways response to cold air. ${ }^{38}$ More importantly, Zileuton has also been shown to improve the severity of day to day asthma. ${ }^{39}$ This inevitably raises the question of the value of allergeninduced asthma as a screen for the efficacy of certain classes of 5-lipoxygenase inhibitors. The dichotomy between efficacy in chronic asthma and in allergen-induced bronchoconstriction was also seen with dietary fish oil supplements which attenuated the late asthmatic response to allergen but had no effect on the severity of day to day asthma. ${ }^{4041} \mathrm{It}$ is interesting that another class of 5-lipoxygenase inhibitors, namely the FLAP inhibitor MK886 , attenuated both the early and late asthmatic responses. ${ }^{42}$ It remains to be established whether different classes of 5-lipoxygenase inhibitors and leukotriene receptor antagonists vary in their clinical profiles.

In summary, despite effective inhibition of 5lipoxygenase, ZD2138 had no significant effect on early and late responses to allergen. This is in contrast to the efficacy of cysteinyl leukotriene receptor antagonists in allergen-induced asthma. Since there is evidence to suggest that 5 -lipoxygenase inhibition is efficacious in the management of bronchial asthma, the value of allergen-induced asthma as a model in which to predict the efficacy of this class of novel agents is questioned.

This study was supported by the National Asthma Campaign.

1 Ford-Hutchinson AW, Bray MA, Doig MV, Shipley ME, Smith MJH. Leukotriene B, a potent chemokinetic and aggregating substance released from polymorphonuclear
leukocytes. Nature 1980;286:264-5.

2 Nagy L, Lee TH, Goetzl EJ, Pickett WC, Kay AB. Complement receptor enhancement and chemotaxis of human neutrophils and eosinophils by leukotrienes and othe lipoxygenase products. Clin Exp Immunol 1982;47:541-7.

3 Lee TH, Sethi T, Crea AEG, Peters W, Arm JP, Horton CE Characterisation of leukotriene $\mathrm{B}_{3}$ : comparison of its biological activities with leukotriene $B_{4}$ and leukotriene $B_{5}$ in complement receptor enhancement, lysozyme release and chemotaxis of human neutrophils. Clin Sci 1988;74:46775.

4 Palmer RMJ, Stepney RJ, Higgs GA, Eakins KE. Chemokinetic activity of arachidonic acid lipoxygenase products on leukocytes of different species. Prostaglandins 1980;20: on leuk.

5 Hoover RL, Karnovsky MJ, Austen KF, Cory EJ, Lewis RA. Leukotriene $B_{4}$ action on endothelium mediates augmented neutrophil/endothelial adhesion. Proc Natl Acad Sci USA 1984;81:2191-3.

6 Showell HJ, Naccache PH, Borgeat P, Picard S, Vallerand P, Becker LE, et al. Characterisation of the secretary activity of leukotriene $\mathrm{B}_{4}$ towards rabbit neutrophils. 7 Immunol 1982;128:811-6.

7 Drazen JM, Austen KF. Leukotrienes and airway responses. Am Rev Respir Dis 1987;136:985-98.

8 Marom Z, Shelhamer JH, Bach MK, Morton DR, Kaliner $M$. Slow reacting substances, leukotrienes $C_{4}$ and $D_{4}$, increase the release of mucus from human airways in vitro. Am Rev Respir Dis 1982;126:449-51.

9 Coles SJ, Neill KH, Reid LM, Austen FK, Nii Y, Corey EJ. Effects of leukotrienes $\mathrm{C}_{4}$ and $\mathrm{D}_{4}$ on glycoprotein and lysozyme secretion by human bronchial mucosa. Prostaglandins 1983;25:155-70.

10 Dahlen S-E, Bjork J, Hedqvist P, Arfors KE, Hammarstrom $\mathrm{S}$, Lindgren JA, et al. Leukotrienes promote plasma leakage and leukocyte adhesion in postcapillary venules: in vivo effects with relevance to the acute inflammatory response. Proc Natl Acad Sci USA 1981;78:3887-91.

11 Drazen JM, Austen KF, Lewis RA, Clark DA, Goto G, Marfat A, et al. Comparative airway and vascular activities of leukotrienes C-1 and D in vivo and in vitro. Proc Natl Acad Sci USA 1980;77:4354-8.

12 Arm JP, Spur BW, Lee TH. The effects of inhaled leukotriene $\mathrm{E}_{4}$ on the airway responsiveness to histamine in subjects with asthma and normal subjects. $\mathcal{f}$ Allergy Clin Immunol 1988;82:654-60.

13 O'Hickey SP, Hawksworth RJ, Fong CY, Arm JP, Spur $\mathrm{BW}$, Lee $\mathrm{TH}$. Leukotrienes $\mathrm{C}_{4}, \mathrm{D}_{4}$ and $\mathrm{E}_{4}$ enhance histamine responsiveness in asthmatic airways. Am Rev Respir Dis 1991;144:1053-7.

14 Lam S, Chan H, LeRiche JC, Chan-Yeung M, Salari H. Release of leukotrienes in patients with bronchial asthma. $\dot{f}$ Allergy Clin Immunol 1988;81:711-7.

15 Crea AEG, Nakhosteen JA, Lee TH. Mediator concentrations in bronchoalveolar lavage fluid of patients with mild asymptomatic bronchial asthma. Eur Respir $f$ 1992;5: $190-5$

16 Wenzel SE, Westcott JY, Larsen GL. Bronchoalveolar lavage fluid mediator levels 5 minutes after allergen challenge in atopic subjects with asthma: relationship to the development of late asthmatic responses. F Allergy Clin Immunol 1991;87:540-8.

17 Wenzel SE, Larsen GL, Johnston K, Voelkel NF, Westcott JY. Elevated levels of leukotriene $\mathrm{C}_{4}$ in bronchoalveolar lavage fluid from atopic asthmatics after endobronchial allergen challenge. Am Rev Respir Dis 1990;142:112-9.

18 Taylor GW, Black P, Turner N, Taylor I, Maltby NH, Turner $\mathrm{N}$, et al. Urinary $\mathrm{LTE}_{4}$ after antigen challenge and in acute asthma and allergic rhinitis. Lancet 1989;i:584-8.

9 Drazen JM, O'Brien J, Sparrow D, Weiss ST, Martins MA, Israel E, et al. Recovery of leukotriene $E_{4}$ from the urine of patients with airway obstruction. Am Rev Respir Dis 1992;146:104-8.

20 Kumlin M, Dahlen B, Bjorck T, Zetterstrom O, Granstrom $\mathrm{E}$, Dahlen S-E. Urinary excretion of leukotriene $\mathrm{E}_{4}$ and 11 dehydro-thromboxane $\mathrm{B}_{2}$ in response to bronchial provodehydro-thromboxane $\mathrm{B}_{2}$ in response to bronchial provo-
cations with allergen, aspirin, leukotriene $\mathrm{D}_{\text {, }}$ and histacations with allergen, aspirin, leukotriene $\mathrm{D}_{4}$, and hista-
mine in asthmatics. Am Rev Respir Dis 1992;146:96-103. mine in asthmatics. Am Rev Respir Dis 1992;146:96-103.
21 Smith CM, Christie PE, Hawksworth RJ, Thien F, Lee TH. Urinary leukotriene $\mathrm{E}_{4}$ levels following allergen and exercise challenge in bronchial asthma. Am Rev Respir Dis 1991;144:1411-3.

22 Manning PJ, Rokach J, Malo JL, Ethier D, Cartier A, Girard $\mathrm{Y}$, et al. Urinary leukotriene $\mathrm{E}_{4}$ levels during early and late asthmatic responses. $\mathcal{F}$ Allergy Clin Immunol 1990;86:21120.

23 Taylor IK, O'Shaughnessy KM, Fuller RW, Dollery CT. Effect of cysteinyl leukotriene receptor antagonist ICI 204,219 on allergen-induced bronchoconstriction and airway hyperreactivity in atopic subjects. Lancet
$1991 ; 337: 690-4$.

24 Findlay SR, Barden JM, Easley CB, Glass M. Effect of the oral leukotriene antagonist ICI 204,219 on antigeninduced bronchoconstriction in subjects with asthma. $\mathcal{f}$ Allergy Clin Immunol 1992;89:1040-5. 
25 Fuller RW, Black PN, Dollery CT. Effect of the ora leukotriene $\mathrm{D}_{4}$ antagonist LY171883 on inhaled and intradermal challenge with antigen and leukotriene $\mathrm{D}_{4}$ in atopic subjects. F Allergy Clin Immunol 1989;83:939-44.

26 Rasmussen JE, Eriksson L-O, Tagari P, Stahl EG, Andersson K-E. Reduced non-specific bronchial reactivity and decreased airway response to antigen challenge in atopic asthmatic patients treated with the inhaled leukotriene $\mathrm{D}_{4}$ antagonist, L648,051. Allergy 1992;47:604-9.

27 McMillan RM, Spruce KE, Crawley GC, Walker ERH, Foster SJ. Pre-clinical pharmacology of ICI D2138, a poster S . Pre-clinical pharmacology of ICI D2138, Br f Pharmacol 1992;107:1042-7.

28 Yates RA, McMillan RM, Ellis SH, Hutchison M, Gilmore $\mathrm{EM}$, Wilkinson DM, et al. A new non-redox 5-lipoxygenase inhibitor ICI D2138 is well tolerated and inhibits blood leukotriene synthesis in healthy volunteers. Am Rev Respir Dis 1992;145:A745.

29 Smith CM, Hawksworth RJ, Thien FC, Christie PE, Lee $\mathrm{TH}$. Urinary leukotriene $\mathrm{E}_{4}$ in bronchial asthma. Eur Respir ₹ 1992;5:693-9.

30 Heavey DJ, Soberman RJ, Lewis RA, Spur BW, Austen KF. Critical considerations in the development of an assay for
sulfidopeptide leukotrienes in plasma. Prostaglandins sulfidopeptide le

31 Bartels H, Bohmer M, Heierli C. Serum kreatininbestimmung ohne enteiweissen. Clin Chim Acta 1972;37:193-7.

32 Carey F, Forder RA. Radioimmunoassay of $\mathrm{LTB}_{4}$ and 6 trans $\mathrm{LTB}_{4}$ : analytical and pharmacological characterisation of immunoreactive $\mathrm{LTB}_{4}$ in ionophore-stimulated human blood. Prostaglandins Leukot Med 1986;22:57-70.

33 Pliss LB, Ingenito EP, Ingram RH, Pichurko B. Assessment of bronchoalveolar cell and mediator response to isocapnic hyperpnoea in asthma. Am Rev Respir Dis 1990;142:73-8. 34 McMillan RM, Girodeau J-M, Foster SJ. Selective chiral inhibitors of 5-lipoxygenase with anti-inflammatory activity. Br F Pharmacol 1990;101:501-3.

35 Hui KP, Taylor IK, Taylor GW, Rubin P, Kesterson J, Barnes NC, et al. Effect of a 5-lipoxygenase inhibitor on leukotriene generation and airway responses after allergen challenge in asthmatic patients. Thorax 1991;46:184-9.

36 Dahlen S-E, Franzen L, Raud J, Serhan CN, Westlund P Wikstrom E, et al. Actions of lipoxin $\mathrm{A}_{4}$ and related compounds in smooth muscle preparations and on the microcirculation in vivo. In: Wong PY-Y, Serhan $\mathrm{CN}$, eds. Lipoxins: biosynthesis, chemistry and biological activities. Ldvances in experimental medicine and biology. New York. Advances in experimental medicine and

37 Christie PE, Spur BW, Lee TH. The effects of lipoxin $\mathrm{A}_{4}$ on airway responses in asthmatic subjects. Am Rev Respir Dis 1992;145:1281-4.

38 Israel E, Dermarkarian R, Rosenberg M, Sperling R, Taylor $\mathrm{G}$, Rubin $\mathrm{P}$, et al. The effects of a 5-lipoxygenase inhibito on asthma induced by cold air. $N$ Engl $f$ Med 1990;323:1740-4.

39 Israel E, Drazen J, Pearlman H, Cohn J, Rubin P. A doubleblind multicenter study of Zileuton, a potent 5-lipoxygenase (5-LO) inhibitor versus placebo in the treatment of nase (5-LO) inhibitor versus placebo in the treatment of
spontaneous asthma in adults (abstract). $\mathcal{f}$ Allergy Clin spontaneous asthma in

40 Arm JP, Horton CE, Mencia-Huerta JM, House F, Eiser NM, Clark TJH, et al. Effect of dietary supplementation with fish oil lipids on mild asthma. Thorax 1988;43:84-92.

41 Arm JP, Horton CE, Spur BW, Mencia-Huerta, J-M, Le TH. The effects of dietary supplementation with fish oil lipids on the airways response to inhaled allergen in bronchial asthma. Am Rev Respir Dis 1989;139:1395-400.

42 Friedman BS, Bel EH, Buntinx A, Tanaka W, Han YHR Shingo S, et al. Oral leukotriene inhibitor (MK 886) blocks allergen-induced airway responses. Am Rev Respir Dis 1993;147:839-44. 